\title{
Materialism, Stress and Health Behaviors among Future Educators
}

\author{
Vasiliki Brouskeli ${ }^{1} \&$ Maria Loumakou $^{2}$ \\ ${ }^{1}$ Department of Educational Studies in Early Childhood, Democritus University of Thrace, Alexandroupoli, Greece \\ ${ }^{2}$ Department of Primary Education, University of Thessaly, Volos, Greece \\ Correspondence: Vasiliki Brouskeli, Department of Educational Studies in Early Childhood, Democritus University of \\ Thrace, Alexandroupoli, P.C. 681 00, Greece.
}

\author{
Received: October 24, 2013 Accepted: November 11, 2013 Online Published: February 10, 2014 \\ doi:10.11114/jets.v2i2.252 \\ URL: http://dx.doi.org/10.11114/jets.v2i2.252
}

\begin{abstract}
In this study we investigated materialism among future educators and its relationship with stress and a number of health behaviors. Participants were 228 students (Mean= 20.64 years of age, $S . D=2.571$ ) of the Department of Education Sciences in Early Childhood of the University of Thrace, Greece.

The instrument consisted of a short form of the Material Values Scale with three subscales, pertaining to the following three domains: possession-defined success, acquisition centrality and acquisition as the pursuit of happiness. Measurements also included the Perceived Stress Scale and questions on several health behaviors. The findings suggested that materialism values were held by $40 \%$ of the participants whereas the component of materialism as happiness pursuit particularly was related to higher levels of stress. Finally, the younger the future educators were the more materialistic values they held. Suggestions for further research are discussed and, considering that children use their educators as models, health promoting interventions that take into account materialism effects are suggested.
\end{abstract}

Keywords: materialism, stress, health behaviors, preschool, educators

\section{Introduction}

Materialism is a complex term and its conceptualization varies across literature. Belk (1984) approached materialism as a trait and defined it as "the importance a consumer attaches to worldly possessions" (p.291), and recognized three sub-traits of it: envy, non-generosity and possessiveness. Richins (1994, p.522) argued that "materialism is a value that represents the individual's perspective regarding the role possessions should play in his/her life". Richins and Dawson (1992) conceptualize three parts of materialism: the centrality of possessions and their acquisition in a person's life, the use of possessions to define the success of others and oneself and the belief that possessions and their acquisition as the pursuit of happiness. Finally, a current expanded conceptualization of materialism refers to "the extent to which individuals attempt to engage in the construction and maintenance of the self through the acquisition and use of products, services, experiences, or relationships that are perceived to provide desirable symbolic value (Shrum et al., 2013, p. 1180). According to this point of view there are multiple identity goals that consumption may be used to achieve, such as self-esteem, continuity and distinctiveness and it is important to understand the motives underlying materialistic goals and behaviors.

Materialism's consequences in a wide range of issues have been well documented in the literature. Materialistic values, for instance, have been negatively associated with subjective well-being (Karabati \& Cemalcilar, 2010) whereas materialistic people exhibit lower levels of self-esteem that reduces their ability to cope with traumatic events (Ruvio, Somer, \& Rindfleisch, 2013). Furthermore, regarding women's self image of their body weight, it has been suggested that a materialistic value orientation is negative in terms of causing dissatisfaction in response to the media and advertising idealized, thin models (Ashikali \& Dittmar, 2012).

As far as copying skills are concerned, materialism has been found to be positively related to parenting stress (Flouri, 2007) as well as to the work-family conflict. Specifically, it is positively related to family interference with work, to work overload, as well as to work interference with family (Promislo, Deckop, Giacalone, \& Jurkiewicz, 2010). In reference to monetary skills, people who endorse materialistic values have more financial worries, worse money-management skills and greater tendency towards compulsive spending, whereas, materialism is a stronger predictor of amount of debt than either income or money-management skills (Garðarsdóttir \& Dittmar, 2012). 
Regarding responsibility skills and behavior, materialistic values are positively related to substance use (Vansteenkiste, Duriez, Simons, \& Soenens, 2006) whereas they have negative effects on environmental beliefs about problems such as ozone depletion, global warming and pollution and these beliefs positively effect environmental concerns and environmentally responsible behaviors (Kilbourne \& Pickett, 2008). Finally, materialism has been suggested as a distinctive social attitude that may predict racism (Roets, Hiel, \& Cornelis, 2006).

Students' materialism is a field of concern for current research. Several studies have been conducted to clarify factors possibly related to students' materialism, such as well-being, distress, substance use (Vansteenkiste et al., 2006), television watching (Ersoy-Quadir, 2012), and the meaning they give to their education (Henderson-King \& Mitchell, 2011).

The purpose of this study was to investigate in a group of exclusively preschool students the relationship of materialism with stress and several health behaviors, either risky, such as smoking and drinking or preventive, such as weight control and exercising. Furthermore, the research aimed to clarify the role of materialism in prospective educators' value system. Finally, the study aimed to explore the relationship of future educators' materialism with their socioeconomic characteristics. To our best knowledge, there are no studies in a preschool student population that have explored materialism relationships to all the above factors simultaneously.

\section{Method}

\subsection{Participant Characteristics}

Participants were 228 students, ranging from 18 to 37 years old (Mean= 20.64, S.D. $=2.571$ ), while $85.4 \%$ of the participants aged between 19-21 years. Almost all participants (98.2\%) were women. Half of the participants stated that their mothers' education level was not above the obligatory for Greece -9 years of education- and almost half of them stated the same for their fathers' education (46.5\%). As far as their socio-economic level is concerned, $85.5 \%$ stated a middle one, $8.3 \%$ a high one and $6.1 \%$ a low one.

\subsection{Sampling Procedures}

During the spring semester of 2012-2013, a broad research project was conducted in the Department of Education Sciences in Early Childhood of the University of Thrace, Greece, which explored future educators' attitudes and evaluations related to health attitudes and behaviors. The data presented in this paper are derived from a larger project and focus on personal evaluated materialism and the factors possibly related to it.

Participation was voluntary and potential respondents were verbally informed about the general aims of the study and the time needed to complete the anonymous questionnaire. Respondents were welcomed to communicate with the researchers in order to be informed for the study results.

\subsection{Measures}

The short version of the Material Values Scale (Richins, 2004) was administered to record materialism as a facet of consumer behavior. It is a 9-item Likert-type measure with three subscales, designed to tap into each of the following three domains: possession-defined success, acquisition centrality and acquisition as the pursuit of happiness. In the first one the possessions are used to judge the success of others and oneself, in the second one the centrality of possessions in a person's life is evaluated and, in the third one, the belief that possessions and their acquisition lead to happiness is measured. In this short form, we increased the number of points on the response scale from five to seven, in order to increase instrument sensitivity and enhance its ability to detect further relationships between materialism and other measured variables (Richins, 2004). The reliability of the scale was assessed by the Cronbach's alpha (.870 for the total scale and $.732, .679$ and .867 for the three subscales respectively). Stress was measured by the Perceived Stress Scale (PSS). It is a 5- point Likert type scale for measuring the degree to which situations of life are appraised as stressful (Cohen Kamarck, \& Mermelstein, 1983). It includes 14 items and it consists of questions such as "In the last month, how often have you been upset because of something that happened unexpectedly?" and, "In the last month, how often have you felt that you were unable to control the important things in your life? The reliability of the scale was quite high (Cronbach's alpha =.831). Back translation was used in order to ensure equivalency of the Greek adaptation for both the above instruments. Furthermore, instruments included scales evaluating the maintenance of smoking habit and the frequency of consuming alcohol. Moreover, it included measures of their self-perceived weight level as well as of the preventive health behaviors of diet control and physical exercise. Finally, four questions were addressed to obtain socio-demographic data about their age, gender, parents' education and family socio-economic level.

\subsection{Data Analysis}

Data were analyzed using SPSS 17.0 for Windows. Descriptive methods included calculation of means and standard deviations or standard errors as well as graphs. Inferential methods included Pearson's correlations, t-tests and analysis 
of variance as well as multivariate analysis of variance when the subscales of materialism were examined for associations with categorical variables. The significance level was set at .05 .

\section{Results}

\subsection{Materialism among Groups}

On the average, prospective teachers' materialistic values were just below the neutral position (Mean=3.73, $\mathrm{SE}=.080$ ). Looking at subscales, the same was true for acquisition in pursuit of happiness (Mean=3.68, SE=.107), while acquisition centrality was just above the neutral position (Mean=4.17, $\mathrm{SE}=.083$ ) and possession-defined success clearly below that (Mean=3.32, $\mathrm{SE}=.091$ ). Although the majority of prospective teachers do not hold materialistic values, about $40 \%$ of them do. Specifically, about half of prospective teachers $(51.3 \%)$ agree with the central role of material acquisition in people's life, a substantial percentage of them (41.2\%) agree with acquisition as the pursuit of happiness but only about one in four $(27.6 \%)$ believe that success is possession defined.

Comparing young students ( $\leq 21$ years old) to those above 21 years old with respect to materialism scales and subscales resulted in significant differences both regarding the materialism total scale and the multivariate comparison of subscales [Wilk's Lamda=.903, $F(3,223)=8.021, P<.001]$. In all cases scores of older students were lower (Table 1).

Table 1. Comparison of materialism total scale and subscales between different age groups

\begin{tabular}{|c|c|c|c|c|c|c|}
\hline & \multicolumn{2}{|c|}{$\begin{array}{c}\text { Young studends } \\
(\mathrm{N}=195)\end{array}$} & \multicolumn{2}{|c|}{$\begin{array}{l}\text { Older students } \\
\quad(\mathrm{N}=32)\end{array}$} & \multirow[t]{2}{*}{$\mathrm{t}$} & \multirow[t]{2}{*}{$\mathrm{P}$} \\
\hline & Mean & S. D. & Mean & S. D. & & \\
\hline Materialism & 3.88 & 1.14 & 2.89 & 1.18 & 4.535 & $<.001$ \\
\hline possession-defined success & 3.47 & 1.32 & 2.48 & 1.37 & 3.918 & $<.001$ \\
\hline acquisition centrality & 4.34 & 1.21 & 3.26 & 1.04 & 4.759 & $<.001$ \\
\hline acquisition as pursuit of happiness & 3.82 & 1.56 & 2.92 & 1.73 & 2.990 & .003 \\
\hline
\end{tabular}

\subsection{Association with Stress}

The mean score for stress was 2.99 ( $S D=.51$ ), corresponding to the middle of the scale, that is "sometimes". In fact, $66 \%$ had average stress levels while $16 \%$ experienced stress "quite often" or "very often". Stress was significantly correlated with materialism, although this positive correlation was weak. Correlations with subscales indicated that stress was associated mainly with acquisition as the pursuit of happiness but not with possession-defined success (Table 2).

Table 2. Correlations of materialism total scale and subscales with Stress

\begin{tabular}{rcc}
\hline & Pearson's Correlation & Stress \\
& & $\begin{array}{c}\text { Significance } \\
P\end{array}$ \\
\hline Materialism & $.204^{* *}$ & .002 \\
\hline possession-defined success & .098 & .141 \\
\hline acquisition centrality & $.143^{*}$ & .031 \\
\hline $\begin{array}{r}\text { acquisition as } \\
\text { the pursuit of happiness }\end{array}$ & $.262^{* *}$ & $<.001$ \\
\hline
\end{tabular}

*. Correlation is significant at the 0.05 level (2-tailed).

**. Correlation is significant at the 0.01 level (2-tailed).

\subsection{Associations with Risk Behaviors}

Materialism was not related to smoking ( 3 groups: 160 no smokers, 50 smoking less than 10 cigarettes per day and 16 smoking more than 10 cigarettes per day). The analysis of variance gave non significant result for the total score $[F(2,223)=.317, P=.729]$ and the multivariate anova for the subscales was similarly non significant [Wilk's Lamda $=.954, F(6,442)=1.770, P=.104]$.

Alcohol consumption was not associated with materialism total score $[F(2,225)=.367, P=.693]$ and the multivariate anova for the subscales did not attain significance [Wilk's Lamda=.954, $F(6,446)=1.805, P=.096]$. It should be noted, though, that univariate tests detected slightly higher scores, on the centrality subscale, among the 34 students consuming more than 3 drinks per week, compared to the 87 students consuming 1-2 drinks per week or the 107 students drinking 
more rarely.

Materialism was not related to physical activity (3 groups: 53 students with no physical activity, 101 rarely exercising and 74 exercising every week). The analysis of variance gave non significant result for the total score $[F(2,225)=.367$, $P=.693$ ] and the multivariate anova for the subscales was also non significant [Wilk's Lamda=.983, $F(6,446)=.633$, $P=$.704]. Similarly no association was found with diet or weight control.

\section{Discussion}

This study revealed the relatively high materialistic values of Greek preschool educators, since even though their majority does not have materialistic values, more than one third of them does. Furthermore, our data suggest that the younger they are the more materialistic values they have. In materialism studies, the role of the educational level as well as the age of the respondents is unclear. It has been proposed that macro characteristics of a country such as economic condition, religious environment and policies applied are as significant as individual background variables, such as age and education, in explaining materialistic attitudes (Kamano, 1999). Greek society is orientated towards consumption and, data for this study were gathered at the time that economic crisis had just commenced. It would be fruitful to repeat the study in the future, so the role of the crisis could be evaluated. However, we must note that teachers as a group have already been pointed out their susceptibility to the market pressures for high levels of consumption (Denegri et al., 2013). In light of the fact that youth is a frequent target group of advertising and their high active in the consuming (Noble, Haytko \& Phillips, 2009), our results suggest to pay extra attention to the materialism influence on the future inexperienced educator.

Our research revealed that prospective educators who value possessions as a means of achieving happiness present higher levels of stress. Materialism has been associated to stress outcomes either directly (Flouri, 2007) or indirectly, as a mediator which diminishes the ability to cope with traumatic stress (Ruvio et al., 2013). Materialism as a happiness pursuit has been also indicated as a mediator which is related to higher levels of family stress reported by adolescents, due to a family disruption, such as a parental divorce (Roberts, Tanner \& Manolis, 2005). Considering the detrimental effects of stress in youth's lives (Landow, 2006) as well as the multiple stressors in a new educator's life (McCarthy, Lambert, \& Ullrich, 2012), we suggest that materialism may be a further burden in preschool educator's every day routine.

Materialistic values were not proved to be related to the health behaviors examined, except possibly for alcohol consumption, as there was only an inclination for more alcohol consumption in students' group who evaluate possessions as having a central role in their lives. Previous research evidence suggests that materialism is related to substance use (Vansteenkiste et.al, 2006) and is a mediating factor to risky behaviors such as unsafe sexual practices, violent behaviors and drug use (Aurbach et al., 2010), suggesting that it could contribute to several physical health problems, in the long run. It seems that materialism is pertinent to the above health harming habits while is not to eating, smoking and exercising in this study.

Participants' gender is an expected limitation when studying a sample of preschool educators. The role of gender as an antecedent of materialistic attitudes is unclear and the relevant conclusions vary (Felix, Ahmed, \& Hinck, 2013; Handa \& Khare, 2013; Karabati \& Cemalcilar, 2010). Apparently, gender role needs further investigation. Moreover, the self-reporting method may allow response distortion and, finally, the cross sectional study design may limit the power of our findings. Longitudinal research would enhance our understanding for the age role as well as the role of the economic crisis role in students' materialistic values. Future research should also clarify materialism dimensions and come to a generally adopted definition, which will allow us to construct instruments that measure the same variables and evaluate the same indicators among different cultural settings in a valid and reliable way. The suggestion that materialistic values should be divided into adaptive- when they constitute motives for a more fulfilling life- and maladaptive -when they become an obsessive drive for material success- resulting in frustration and inability to develop full range of human potential (Tobacyk et al., 2011) seems reasonable.

The crucial role of preschool educators in children's life has been generally recognized and therefore they need to offer adequate models. A sufficient early childhood teacher model usually underlies our deep appreciation for children and childhood (Feeney, Moravcik, Nolte, \& Christensen, 2010), consequently, this role model should be prepared adequately. Their health orientated courses should include topics about the meaning as well as the potential consequences of a materialistic orientation in life. Furthermore, psychosocial services should be available and competent to counsel for relative issues, in order to protect them and keep them aware of the risks.

\section{Conclusion}

This study demonstrated that preschool educators with high levels of materialistic values tend to report higher levels of stress. Moreover, it seems that, the younger the prospective educators are, the more materialistic they tend to be. An 
overestimation of the security role of materialistic possessions may lead to the development of strong materialistic attitudes, and to materialistic orientated behaviors that would neglect crucial humanistic principles and cause physical and psychological harm. Since preschool children tend to pattern themselves after their educators, future interventions promoting a healthy educator's model should take into account the effects of materialism and redirect the pedagogical students to community contribution and person-orientated values.

\section{References}

Ashikali, E. M., \& Dittmar, H. (2012). The effect of priming materialism on women's responses to thin-ideal media. British Journal of Social Psychology, 51, 514-533. http://dx.doi.org/ 10.1111/j.2044-8309.2011.02020.x

Aurbach, R. P., McWinnie, C. M., Goldfinger, M., Abela, J. R. Z., Zhu, X., \& Yao, S. (2010). The cost of materialism in a collectivistic culture: predicting risky behavior engagement in Chinese adolescents. Journal of Clinical Child \& Adolescent Psychology, 39(1), 117-127.

Belk, R. W. (1984). Three scales to measure constructs related to materialism: reliability, validity, and relationships to measures of happiness. In T. Kinear (Ed.), Advances in Consumer Research (pp. 291-297). Provo, UT: Association for Consumer Research.

Cohen, S., Kamarck, T., \& Mermelstein, R. (1983). A global measure of perceived stress. Journal of Health and Social Behavior, 24 (4), 385-396.

Denegri, M., Baeza, M.J., Salinas-Oñate, N., Peñaloza, V., Miranda, H., \& Orellana, L. (2013). Materialism in Pedagogy students in Chile. Social Indicators Research, 1-17. http://dx.doi.org/ 10.1007/s11205-013-0358-z

Ersoy-Quadir, S. (2012). An analysis of some of the factors behind materialism among university students in Turkey. Journal of Adult Development, 19, 79-87. http://dx.doi.org/10.1007/s10804-011-9136-9

Feeney, S., Moravcik, E., Nolte, S., \& Christensen, D. (2010). Who am I in the lives of children? (8th ed.). Upper Suddle River, NJ: Pearson Education.

Felix, R., Ahmed, Z. U., \& Hinck, W. (2013). Gender issues in consumer materialism: the case of Mexico. Journal of Transnational Management, 18, 82-100. http://dx.doi.org/10.1080/15475778.2013.782230

Flouri, E. (2007). The relationship between parenting and materialism in British mothers and fathers of secondary school age children. The Journal of Socio-Economics, 36, 167-176.

Garðarsdóttir, R. B., \& Dittmar, H. (2012). The relationship of materialism to dept and financial well-being: the case of Iceland's perceived prosperity. Journal of Economic Psychology, 33, 471-481.

Handa, M., \& Khare, A. (2013). Gender as a moderator of the relationship between materialism and fashion clothing involvement among Indian youth. International Journal of Consumer Studies, 37, 112-120. http://dx.doi.org/10.1111/j.1470-6431.2011.01057.x

Henderson-King D., \& Mitchell, A. M. (2011). Do materialism, intrinsic aspirations, and meaning in life predict students' meanings of education? Social Psychology of Education, 14, 119-134. http://dx.doi.org/10.1007/s11218-010-9133-z

Kamano, S. (1999). Comparing individual attitudes in seven countries. Social Science Research, 28, 1-35.

Karabati, S., \& Cemalcilar, Z. (2010). Values, materialism, and well-being: a study with Turkish university students. Journal of Economic Psychology, 31, 624-633.

Kilbourne, W., \& Pickett, G. (2008). How materialism affects environmental beliefs, concern, and environmentally responsible behavior. Journal of Business Research, 61, 885-893.

Landow, M. V. (Ed.) (2006). Stress and mental health of college students. New York: Nova Science Publishers.

McCarthy, C., Lambert, R., \& Ullrich, A. (Eds.) (2012). International Perspectives on Teacher Stress. Charlotte, NC: Information Age Publishing.

Noble, S. M., Haytko, D. L., \& Phillips, J. (2009). What drives college- age Generation Y consumers? Journal of Business Research, 62, 617-628. http://dx.doi.org/10.1016/j.jbusres.2008.01.020

Roberts, J. A., Tanner, J. F., \& Manolis, C. (2005). Materialism and the family-structure-stress relation. Journal of Consumer Psychology, 15(2), 183-190.

Promislo, M. D., Deckop, J. R., Giacalone, R. A., \& Jurkiewicz, C. L. (2010). Valuing money more than people: the effects of materialism on work-family conflict. Journal of Occupational Psychology, 83, 935-953.

Richins, M. L. (1994). Special possessions and the expression of material values. Journal of Consumer Research, 21, 
$522-533$.

Richins, M. L. (2004). The Material Values Scale: measurement properties and development of a short form. Journal of Consumer Research, 31, 209-219.

Richins, M. L., \& Dawson, S. (1992). A consumer values orientation for materialism and its measurement: scale development and validation. Journal of Consumer Research, 19, 303-316.

Roberts, J. A., Tanner, J. F., \& Manolis, C. (2005). Materialism and the family-structure-stress relation. Journal of Consumer Psychology, 15(2), 183-190.

Roets, A., van Hiel, A., \& Cornelis, I. (2006). Does materialism predict racism? Materialism as a distinctive social attitude and a predictor of prejudice. European Journal of Personality, 20, 155-168.

Ruvio, A., Somer, E., \& Rindfleisch, A. (2013). When bad gets worse: the amplifying effect of materialism on traumatic stress and maladaptive consumption. Journal of Academy of Marketing Science, 1-12. http://dx.doi.org/ 10.1007/s11747-013-0345-6

Shrum, L .J., Wong, N., Arif, F., Chugani, S. K., Gunz, A., Lowrey, T. M., Nairn, A., Pandelaere, M., Ross, S.M., Ruvio, A., Scott, K., \& Sundie, J. (2013). Reconceptualizing materialism as identity goal pursuits: Functions, processes, and consequences. Journal of Business Research, 66, 1179-1185. http://dx.doi.org/10.1016/j.jbusres.2012.08.010

Tobacyk, J. J., Babin, B. J., Attaway, J. S., Socha, S., Shows, D., \& James, K. (2011). Materialism through the eyes of Polish and American consumers. Journal of Business Research, 64, 944-950. http://dx.doi.org/10.1016/j.jbusres.2010.11.016

Vansteenkiste, M., Duriez, B., Simons, J., \& Soenens, B. (2006). Materialistic values and well-being among business students: further evidence of their detrimental effect. Journal of Applied Social Psychology, 36, 2892-2908.

\section{(c)) EY}

This work is licensed under a Creative Commons Attribution 3.0 License. 